\title{
Testing adsorbents capacities for indoor volatile organic compounds at optimum operating conditions
}

\author{
W. S. Bouhamra, A. S. Elkilani \& C. G. J. Baker \\ Department of Chemical Engineering, Kuwait University, Kuwait
}

\begin{abstract}
Measurements of adsorption isotherms for three VOCs (toluene, 1,2 dichlorobenzene and 1,1,1 trichloroethane) on five adsorbents (polyacrylonitrile carpet fibers, silica alumina, silica alumina impregnated with $\mathrm{KMnO}_{4}$, granulated activated carbon and pellets of activated carbon) were performed. Various temperatures and relative humidity were tested. VOCs concentrations were altered in the range of presence in indoor environments in Kuwait. The adsorbed weight was measured in a thermogravimetric analyser. Linear isotherms were observed in all cases with values of the Henry coefficient ranging from 0.01 to $0.941 \mathrm{~mm}$. Silica alumina activated by $\mathrm{KMnO}_{4}$ showed highest adsorption rates. At low temperatures and minimum humidity in air high equilibrium constants were observed, since adsorption rate is higher than desorption rates at lower temperatures. In addition, increasing humidity will decrease adsorption rates due to moisture occupation of the available voids for adsorption, especially for hydrophilic adsorbents. There was good agreement between the equilibrium and kinetic constants obtained in the TGA. It may therefore be concluded that, in the present case at least, adsorption data obtained using small samples of adsorbent in the laboratory can be successfully scaled-up and used in combination with the theory described in this work to model indoor air quality in much larger chambers.
\end{abstract}

\section{Introduction}

Volatile Organic Compounds (VOCs) may present an IAQ problem, when individual organic compounds or their mixtures exceed certain concentrations. Most of VOCs are classified as carcinogens. In theory, the removal of gaseous 
contaminants from indoor air, or from outdoor air drawn into ventilation systems, can be achieved by adsorption. In the present context, adsorbate species are transported via convection and molecular diffusion processes from the bulk air phase to locations near the adsorbent boundaries. At these boundaries, diffusion processes take over to move the adsorbate first through the boundary layer surrounding the adsorbent and then through the porous interstices of the adsorbent to surface locations close to the solid portions of the material. Finally, the actual adsorption processes bind the adsorbate to activated adsorbent surface locations.

The large internal surface area of sorbents provides a favorable medium for chemical reactions. These surfaces can be coated or impregnated with chemicals that will selectively react with or chemisorb molecules from a gas stream. Activated alumina impregnated with potassium permanganate $\left(\mathrm{KMnO}_{4}\right)$ is used in air-cleaning systems. It is best known by the trade names Purafil and Carasorb. Though activated alumina does not have the adsorptive power of most activated carbons, it can be used effectively for the control of a variety of contaminant gases, including formaldehyde and ethylene. However, adsorption on activated alumina is irreversible until the operating conditions are changed in an approprite manner.

The specific air pollution problem that can be solved, based on the outcome of this study, is the presence of carcinogenic volatile organic compounds (VOCs) indoor especially at homes. Some previous published studies [1, 2] of the authors showed the presence of high levels of benzene and chlorinated VOCs in 100 houses in Kuwait. Health risk assessment was calculated based on the detected concentration and it was high compared to international levels. Studying different adsorbents at various ambient conditions (temperature and humidity) is a step to build stand alone units with filters that contain these adsorbents specially those with the highest capacity to adsorb the indoor VOCs. The cost of these units will not depend only on the adsorbent filter but also on the air suction pump as fixed cost and replaced or regenerated filters as an operating cost.

The present study objective is to obtain the adsorption and desorption rate constants for characteristic VOCs on five selected adsorbents.

\section{Experimental}

Measurements of the adsorption isotherms were performed on a TGA-51 thermogravimetric analyzer manufactured by the Shimadzu Corporation in Japan. The experiments were carried out at four different temperatures, $25^{\circ} \mathrm{C}$, $30^{\circ} \mathrm{C}, 35^{\circ} \mathrm{C}$ and $45^{\circ} \mathrm{C}$ and a range of VOC concentrations (1-1000) ppm. Five adsorbents, polyacrylonitrile fibers, silica alumina, silica alumina impregnated with $\mathrm{KMnO}_{4}$, activated carbon granules and activated carbon pellets were tested. Before use, the adsorbents were refreshed by passing zero air over them for $24 \mathrm{~h}$. In addition, further experiments were carried out at five different relative humidity, $0 \%, 5 \%, 10 \%, 20 \%$ and $30 \%$ each at fixed temperature.

The desired concentration of the organic vapor in air was prepared in the laboratory by injecting a known amount of VOC into a one-liter tedlar air bag (Supelco) using an appropriate microvolume syringe. Zero air was again used 
for this purpose. Each experiment was performed as follows. One liter of the VOC/air mixture was injected through the balance chamber of $73.63-\mathrm{cm}^{3}$ volume with the outlet valve open to flush out the existing air and to ensure that the concentration inside the TGA was the same as that in the tedlar air bag. Since the volume of injected VOC/air mixture was around 14 times that of the balance chamber, it can be assumed that the initial air in the chamber was completely flushed out. The inlet and outlet valves were then closed and the fiber weight and temperature were measured as a function of time until constant values were attained (i.e. the system had reached equilibrium). The same procedure was repeated for all VOCs and at different temperatures (each run took around two hours).

\section{Modeling}

In the experiments performed in the TGA-51, the rate of change of the bulk air concentration and the sorbed weight per unit surface area can be described by the following equations [3]:

$$
\begin{gathered}
\frac{\mathrm{dC}_{\mathrm{b}}}{\mathrm{dt}}=-\mathrm{k}_{\mathrm{a}}\left(\mathrm{A}_{\mathrm{bet}} / \mathrm{V}_{\text {tga }}\right) \mathrm{C}_{\mathrm{b}}+\mathrm{k}_{\mathrm{d}}\left(\mathrm{A}_{\mathrm{bet}} / \mathrm{V}_{\mathrm{tga}}\right) \mathrm{C}_{\mathrm{s}} \\
\frac{\mathrm{dC}_{\mathrm{s}}}{\mathrm{dt}}=\mathrm{k}_{\mathrm{a}} \mathrm{C}_{\mathrm{b}}-\mathrm{k}_{\mathrm{d}} \mathrm{C}_{\mathrm{s}}
\end{gathered}
$$

Here,

$\mathrm{A}_{\text {bet }}=$ BET surface area of the adsorbent, $\mathrm{m}^{2} / \mathrm{g}$

$\mathrm{C}_{\mathrm{b}}=$ Bulk VOC concentration in the TGA chamber, $\mathrm{mg} / \mathrm{m}^{3}$

$\mathrm{C}_{\mathrm{s}}=$ Sorbed weight per unit surface area, $\mathrm{mg} / \mathrm{m}^{2}$

$\mathrm{k}_{\mathrm{a}}=$ Adsorption rate constant, $\mathrm{m} / \mathrm{h}$

$\mathrm{k}_{\mathrm{d}} \quad=$ Desorption rate constant, $1 / \mathrm{h}$

$\mathrm{t} \quad=$ Time, $\mathrm{h}$

$\mathrm{V}_{\text {tga }}=$ Volume of the TGA chamber, $\mathrm{m}^{3}$

Note that the rate of adsorption $\left(\mathrm{k}_{\mathrm{a}} \mathrm{C}_{\mathrm{b}}\right)$ is not equal to the rate of desorption $\left(\mathrm{k}_{\mathrm{d}} \mathrm{C}_{\mathrm{s}}\right)$ unless the system has reached equilibrium and the sorbed weight per unit surface area remains constant.

The relation between the amount adsorbed on the solid and the concentration in the bulk air is called an isotherm. For adsorption on a uniform surface at sufficiently low concentration, Henry's law applies. This can be expressed in terms of concentration as [4]:

$$
\mathrm{C}_{\mathrm{s}}=H \mathrm{C}_{\mathrm{b}}
$$

where the equilibrium constant $H$ is known as the Henry constant. It follows from Eqs. (2) and (3) that $H=\mathrm{k}_{\mathrm{a}} / \mathrm{k}_{\mathrm{d}}$, since at equilibrium the rate of adsorption equals rate of desorption.

The final concentration $\left(C_{b}\right)$ of VOC in the bulk air in the balance chamber was calculated from the experimental data. Also, the sorbed weight of VOC per unit area $\left(\mathrm{C}_{\mathrm{s}}\right)$ was calculated from the measured final sorbed weight, the specific surface area of adsorbents and the weight of. 
The temperature dependence of the Henry constant can be described by the van't Hoff equation:

$$
\frac{\mathrm{d} \ln H}{\mathrm{dT}}=\frac{\Delta \mathrm{U}_{\mathrm{o}}}{\mathrm{RT}^{2}}
$$

where the activation energy $\Delta \mathrm{U}_{\mathrm{o}}$ is the difference between the internal energies of the adsorbate in the adsorbed and gaseous states, $\mathrm{T}$ is the absolute temperature, and $\mathrm{R}$ is the gas constant. Integration of Eq. (4) yields:

$$
H=H_{\mathrm{o}} \mathrm{e}^{-\frac{\Delta \mathrm{U}_{\mathrm{o}}}{\mathrm{RT}}}
$$

Table 1: $\quad$ Measured and calculated data for 1,1,1 trichloroethane on polyacrylonitrile fibers at $25{ }^{\circ} \mathrm{C}$ in the TGA-51.

\begin{tabular}{|c|c|c|c|c|}
\hline $\begin{array}{c}\text { Initial } \\
\text { concentration } \\
\text { of VOC in air } \\
\left(\mathrm{mg} / \mathrm{m}^{3}\right)\end{array}$ & $\begin{array}{c}\text { Weight of } \\
\text { fibers } \\
(\mathrm{mg})\end{array}$ & $\begin{array}{c}\text { Sorbed } \\
\text { weight } w_{s} \\
(\mathrm{mg})\end{array}$ & $\begin{array}{c}\text { Final concentration of } \\
\text { VOC in air } \\
C_{b} \\
\left(\mathrm{mg} / \mathrm{m}^{3}\right)\end{array}$ & $\begin{array}{c}\text { Sorbed weight per } \\
\text { unit area } \\
C_{s} \\
\left(\mathrm{mg} / \mathrm{m}^{2}\right)\end{array}$ \\
\hline 620 & 85.66 & 0.015 & 415.90 & 0.0936 \\
\hline 829 & 114.53 & 0.015 & 624.93 & 0.1236 \\
\hline 1,519 & 85.65 & 0.017 & 1288 & 0.1401 \\
\hline 1,991 & 85.66 & 0.025 & 1651 & 0.2060 \\
\hline 4,519 & 92.65 & 0.048 & 3867 & 0.3657 \\
\hline 5,332 & 92.66 & 0.062 & 4489.50 & 0.4723 \\
\hline 10,423 & 84.96 & 0.107 & 9028 & 0.8931 \\
\hline 17,198 & 60.01 & 0.125 & 15500 & 1.55 \\
\hline
\end{tabular}

\section{Results and discussion}

In each experiment, the initial concentration of VOC inside the TGA chamber and the adsorbent weight as a function of time were measured. The final concentration of VOC in the bulk air inside the chamber and the sorbed weight of VOC per unit (BET) area were calculated by means of a material balance. Table 1 summarizes the results of a typical set of measurements for $1,1,1$ trichloroethane/polyacrylonitrile fibers at $25{ }^{\circ} \mathrm{C}$. In these runs, the initial concentration of VOC in the bulk air and the adsorbent weight were varied. Also shown in the table are the corresponding values of the measured increase in the weight of the adsorbent (the sorbed weight $\mathrm{w}_{\mathrm{s}}$ ), the calculated values of the final concentration of VOC in the bulk air $\mathrm{C}_{\mathrm{b}}$ and the sorbed weight per unit area $\mathrm{C}_{\mathrm{s}}$. As may be seen from the data presented in this table, the sorbed weight of $\operatorname{VOC}\left(\mathrm{w}_{\mathrm{s}}\right)$ increased when the initial concentration of $1,1,1$ trichloroethane in the VOC/air mixture was increased. This trend was apparent at all temperatures studied and for all VOCs. 
The sorbed weight per unit area of polyacrylonitrile $\left(\mathrm{C}_{\mathrm{s}}\right)$ is plotted against bulk air concentration $\left(\mathrm{C}_{\mathrm{b}}\right)$ for the different VOCs at four different temperatures $\left(25^{\circ} \mathrm{C}, 30^{\circ} \mathrm{C}, 35^{\circ} \mathrm{C}\right.$, and $\left.45^{\circ} \mathrm{C}\right)$ in Figure 1 . As shown in Figure 1, the sorbed weight per area $\left(\mathrm{C}_{\mathrm{s}}\right)$ increased linearly with the bulk air concentration $\left(\mathrm{C}_{\mathrm{b}}\right)$ of toluene at all four temperatures studied. Similar trends were observed for 1,1,1 trichloroethane and 1,2 dichlorobenzene. The linearity of these plots confirms that Henry's law was obeyed in all cases, which can be anticipated given the low concentrations of VOC employed in the experiments. The slope of each line in Figure 1 is the Henry constant $H$, which is listed in Table 2 for each VOC under study.

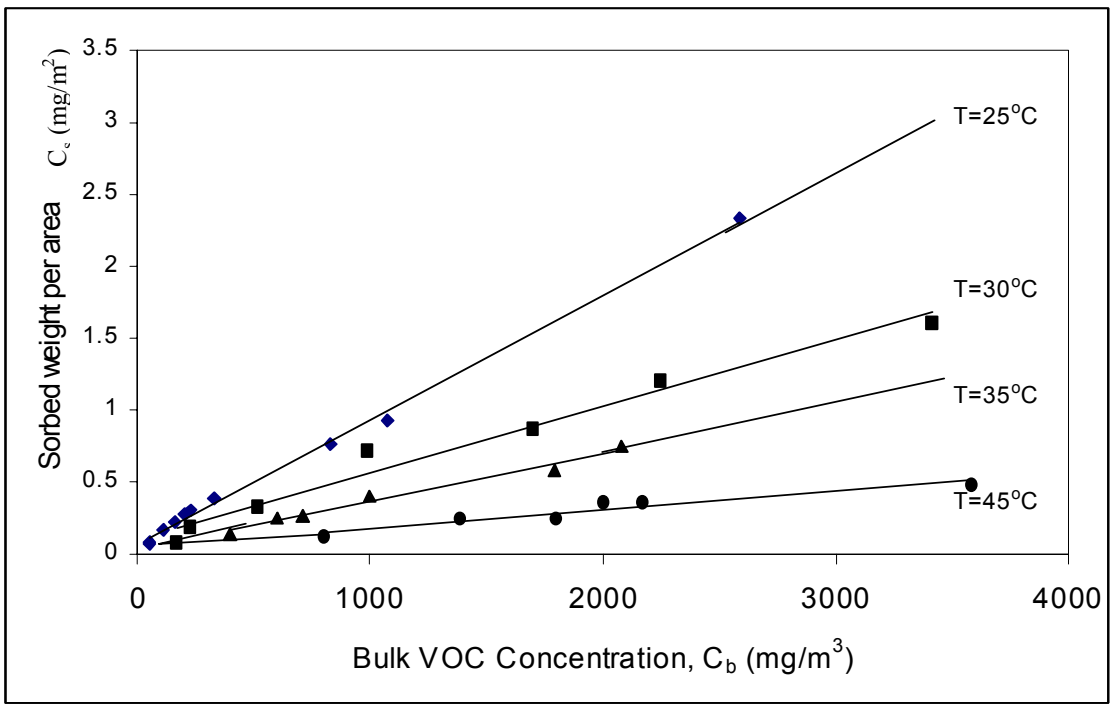

Figure 1: $\quad$ Sorbed weight per unit area versus bulk VOC concentration for 1,2 dichlorobenzene on polyacrylonitrile fibers at different temperatures.

Plots of $\ln H$ versus 1/T, based on the van't Hoff equation, for the three VOCs are shown in Figure 2. These were found to be essentially linear over the temperature range studied. In all cases, the value of $H$ decreased with increasing temperature. The slope which is related to the activation energy is consistent with physical adsorption.

The adsorption and desorption rate constants, $\mathrm{k}_{\mathrm{a}}$ and $\mathrm{k}_{\mathrm{d}}$, respectively, were determined from the plots of sorbed weight as a function of time. Typical values of sorbed weight per unit surface area $\left(\mathrm{C}_{\mathrm{s}}\right)$ and bulk concentration $\left(\mathrm{C}_{\mathrm{b}}\right)$ as functions of time are listed in Table 3 for toluene at $40^{\circ} \mathrm{C}$. These data were used to derive values of $k_{a}$ and $k_{d}$ from equations (1) and (2). This procedure was repeated for each TGA experiment. Table 2 lists individual $k_{a}$ and $k_{d}$ values along with the calculated ratios of $k_{e}=k_{a} / k_{d}$, which are comparable with the Henry constants. 


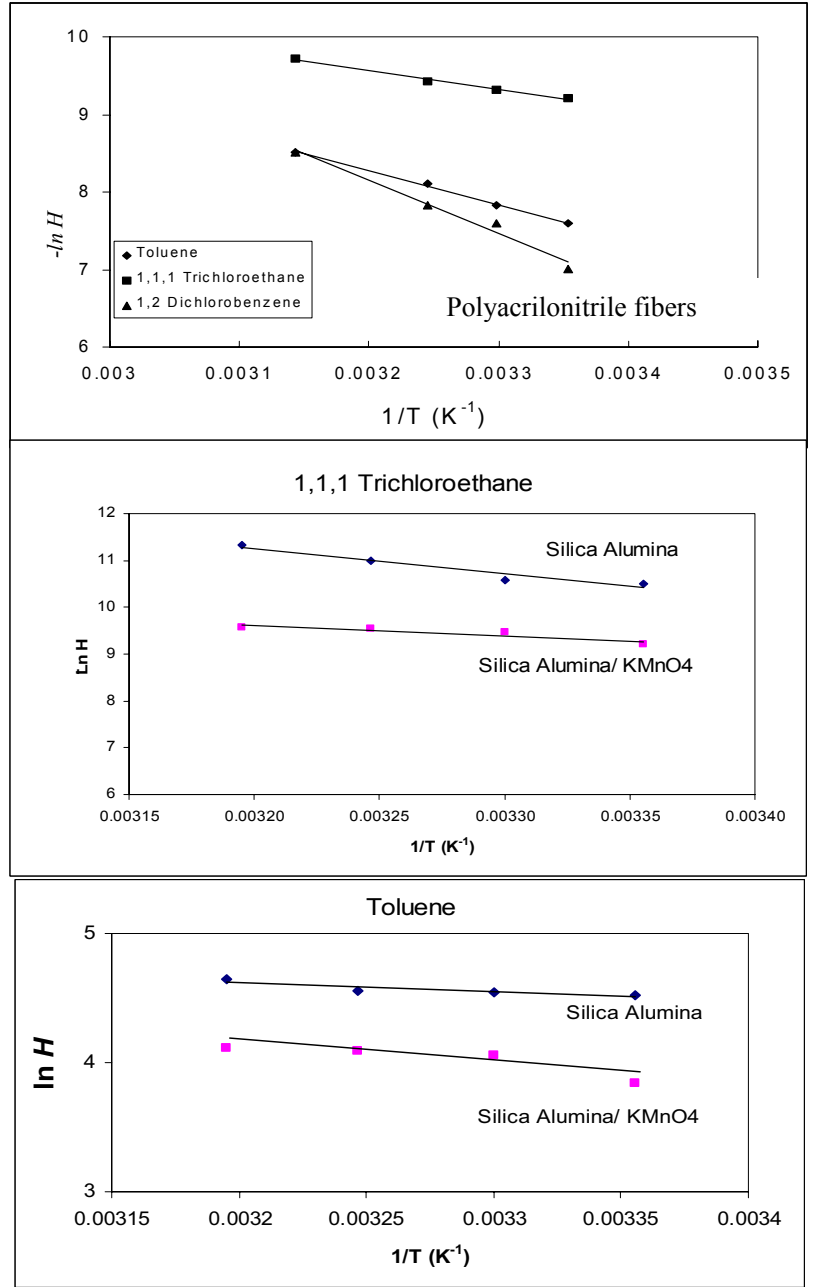

Figure 2: Van't Hoff plots.

Varying the operating conditions for adsorption was required to simulate the actual indoor environment. In all the previous experiments zero air with approximately zero humidity was used. In this section relative humidity of the air was controlled via a humidifier. As discussed earlier in the experimental section of the preparation of different concentrations of a VOC in air, this air is no more zero air, rather it contains known amount of moisture. The relative humidity of air was varying in the range from $5 \%$ to $30 \%$. In each experiment temperature was kept constant. Figure 3 show toluene at $25{ }^{\circ} \mathrm{C}$ activated carbon granules at relative humidity range from $5 \%$ to $30 \%$. 
Table 2: Adsorption/desorption rate, equilibrium constants and Henry constants.

\begin{tabular}{|c|c|c|c|c|c|c|c|c|}
\hline \multicolumn{9}{|c|}{ Polyacronitrile fibers } \\
\hline \multirow[b]{2}{*}{ Temperature } & \multicolumn{3}{|c|}{ Toluene } & \multicolumn{2}{|c|}{ 1,2 Dichlorobenzene } & \multicolumn{3}{|c|}{ 1,1,1 Trichloroethane } \\
\hline & \multicolumn{2}{|c|}{$25^{\circ} \mathrm{C}$} & $45^{\circ} \mathrm{C}$ & $25^{\circ} \mathrm{C}$ & $45^{\circ} \mathrm{C}$ & \multicolumn{2}{|c|}{$25^{\circ} \mathrm{C}$} & $45^{\circ} \mathrm{C}$ \\
\hline $\mathrm{k}_{\mathrm{a}} \times 10^{6}, \mathrm{~m} / \mathrm{h}$ & \multicolumn{2}{|c|}{19.2} & 13.1 & 12.7 & 11.6 & \multicolumn{2}{|c|}{13.7} & 9.7 \\
\hline $\mathrm{k}_{\mathrm{d}}, 1 / \mathrm{h}$ & \multicolumn{2}{|c|}{0.032} & 0.07 & 0.014 & 0.06 & \multicolumn{2}{|c|}{0.13} & \multirow{2}{*}{$\begin{array}{c}0.17 \\
0.058\end{array}$} \\
\hline $\mathrm{k}_{\mathrm{e}}, \mathrm{mm}$ & \multicolumn{2}{|c|}{0.60} & 0.187 & 0.9 & 0.193 & \multicolumn{2}{|c|}{0.105} & \\
\hline $\mathrm{H}, \mathrm{mm}$ & \multicolumn{2}{|c|}{0.51} & 0.201 & 0.941 & 0.213 & \multicolumn{2}{|c|}{0.108} & 0.063 \\
\hline \multicolumn{9}{|c|}{ Silica Alumina (SAl) and Silica Alumina impregnated with $\mathrm{KMnO}_{4}(\mathrm{SAl} / \mathrm{K})$} \\
\hline \multirow[b]{2}{*}{ Temperature } & \multicolumn{4}{|c|}{ Toluene } & \multicolumn{4}{|c|}{ 1,1,1 Trichloroethane } \\
\hline & \multicolumn{2}{|c|}{$25^{\circ} \mathrm{C}$} & \multicolumn{2}{|c|}{$40^{\circ} \mathrm{C}$} & 25 & & & ${ }^{\circ} \mathrm{C}$ \\
\hline Adsorbent & SAl & $\mathrm{SAl} / \mathrm{K}$ & SAl & $\mathrm{SAl} / \mathrm{K}$ & SAl & $\mathrm{SAl} / \mathrm{K}$ & SAl & $\mathrm{SAl} / \mathrm{K}$ \\
\hline $\mathrm{k}_{\mathrm{a}} \times 10^{6}, \mathrm{~m} / \mathrm{h}$ & 58 & 62 & 28.1 & 37.8 & 61 & 63 & 20 & 56 \\
\hline $\mathrm{k}_{\mathrm{d}}, 1 / \mathrm{h}$ & 1.9 & 1.44 & 1.2 & 0.51 & 2.6 & 0.66 & 1.3 & 0.82 \\
\hline $\mathrm{k}_{\mathrm{e}}, \mathrm{mm}$ & 0.03 & 0.043 & 0.023 & 0.075 & 0.024 & 0.095 & 0.015 & 0.069 \\
\hline$H, \mathrm{~mm}$ & 0.03 & 0.014 & 0.022 & 0.076 & 0.027 & 0.101 & 0.012 & 0.07 \\
\hline Act & $\mathrm{d}$ Carl & on Pellet & $\mathrm{s}(\mathrm{ACP}) \mathrm{a}$ & d Activat & d Carbon & Granules & (ACG) & \\
\hline & & & oluene & & & $1,1,1$ Tric & chloroetha & \\
\hline Temperature & $25^{\circ} \mathrm{C}$ & & $35^{\circ} \mathrm{C}$ & & $25^{\circ} \mathrm{C}$ & & $35^{\circ} \mathrm{C}$ & \\
\hline Adsorbent & $\mathrm{ACP}$ & ACG & ACP & ACG & ACP & ACG & $\mathrm{ACP}$ & $\begin{array}{c}\mathrm{AC} \\
\mathrm{G}\end{array}$ \\
\hline $\mathrm{k}_{\mathrm{a}} \times 10^{6}, \mathrm{~m} / \mathrm{h}$ & 60 & 61 & 35 & 33 & 63 & 60 & 30 & 31 \\
\hline $\mathrm{k}_{\mathrm{d}}, 1 / \mathrm{h}$ & 2.7 & 2.65 & 3.21 & 3.14 & 2.1 & 1.94 & 1.69 & 1.77 \\
\hline $\mathrm{k}_{\mathrm{e}}, \mathrm{mm}$ & 0.02 & 0.02 & 0.011 & 0.011 & 0.030 & 0.031 & 0.018 & 0.018 \\
\hline $\mathrm{H}, \mathrm{mm}$ & 0.02 & 0.023 & 0.011 & 0.010 & 0.028 & 0.028 & 0.017 & 0.017 \\
\hline
\end{tabular}

Table 3: $\quad$ Typical dynamic data for the adsorption of toluene at $40^{\circ} \mathrm{c}$ by silica alumina impregnated with $\mathrm{KMnO}_{4}$.

\begin{tabular}{|c|c|c|c|}
\hline Time $(\mathrm{min})$ & Sorbed weight $\mathrm{w}_{\mathrm{s}}(\mathrm{mg})$ & $\mathrm{C}_{\mathrm{b}}\left(\mathrm{mg} / \mathrm{m}^{3}\right)$ & $\mathrm{C}_{\mathrm{s}}\left(\mathrm{mg} / \mathrm{m}^{2}\right)$ \\
\hline 0 & 0 & 500 & 0 \\
\hline 10 & 1.3 & 482.3442 & 0.007838 \\
\hline 20 & 1.6 & 478.2697 & 0.009647 \\
\hline 30 & 1.9 & 474.1953 & 0.011455 \\
\hline 40 & 2.1 & 471.479 & 0.012661 \\
\hline 50 & 2.4 & 467.4046 & 0.01447 \\
\hline 60 & 2.6 & 464.6883 & 0.015676 \\
\hline 70 & 2.9 & 460.6139 & 0.017484 \\
\hline 80 & 3.1 & 457.8976 & 0.01869 \\
\hline 90 & 3.25 & 455.8604 & 0.019595 \\
\hline 100 & 3.4 & 453.8232 & 0.020499 \\
\hline 110 & 3.6 & 451.1069 & 0.021705 \\
\hline 120 & 3.8 & 448.3906 & 0.022911 \\
\hline 130 & 3.9 & 447.0325 & 0.023513 \\
\hline
\end{tabular}




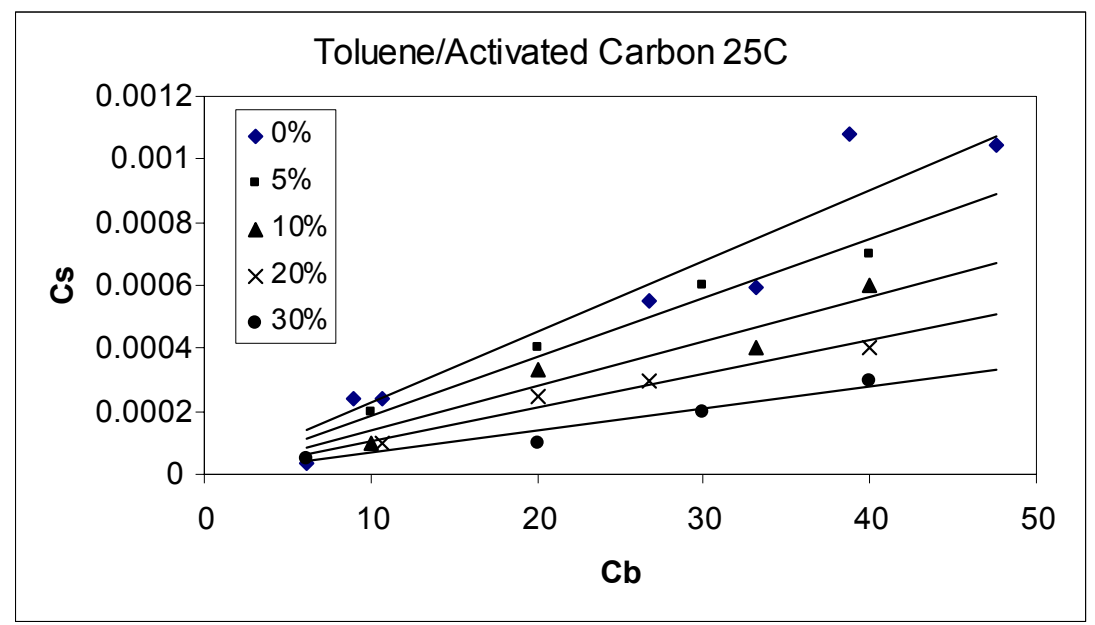

Figure 3: Toluene bulk concentration versus sorbed concentration on activated carbon granules at different relative humidity.

It can be observed from Figure 3 that increasing relative humidity decreases sorbed concentration at the same conditions of bulk concentration and temperature. Table 4 shows the trends of Henry constant with relative humidity for all tested systems. It can be observed from Figure 4 that the Henry constant decreases with increasing relative humidity since the moisture occupies some of the sites available for adsorption and hence decreases the VOC adsorption capacity.

Table 4: $\quad$ Henry constant $(\mathrm{mm})$ at various relative humidity.

\begin{tabular}{|l|l|l|l|l|l|}
\hline \multirow{2}{*}{ System } & \multicolumn{5}{c|}{ Relative Humidity } \\
\cline { 2 - 6 } & $\mathbf{0 \%}$ & $\mathbf{5 \%}$ & $\mathbf{1 0 \%}$ & $\mathbf{2 0 \%}$ & $\mathbf{3 0 \%}$ \\
\hline $\begin{array}{l}\text { Toluene/activated } \\
\text { carbon at } 25^{\circ} \mathrm{C}\end{array}$ & 0.023 & 0.019 & 0.014 & 0.011 & 0.007 \\
\hline $\begin{array}{l}\text { Toluene/activated } \\
\text { carbon at } 35^{\circ} \mathrm{C}\end{array}$ & 0.010 & 0.008 & 0.006 & 0.004 & 0.003 \\
\hline $\begin{array}{l}\text { Trichloroethane/ } \\
\text { activated carbon } 25^{\circ} \mathrm{C}\end{array}$ & 0.028 & 0.02 & 0.014 & 0.009 & 0.007 \\
\hline $\begin{array}{l}\text { Trichloroethane/ } \\
\text { activated carbon } 35^{\circ} \mathrm{C}\end{array}$ & 0.017 & 0.013 & 0.011 & 0.009 & 0.008 \\
\hline $\begin{array}{l}\text { Toluene/ silica } \\
\text { alumina at } 25^{\circ} \mathrm{C}\end{array}$ & 0.03 & 0.019 & 0.014 & 0.011 & 0.008 \\
\hline $\begin{array}{l}\text { Toluene/ silica } \\
\text { alumina } 35^{\circ} \mathrm{C}\end{array}$ & 0.029 & 0.015 & 0.012 & 0.008 & 0.005 \\
\hline $\begin{array}{l}\text { Trichloroethane/ } \\
\text { silica alumina } 25^{\circ} \mathrm{C}\end{array}$ & 0.028 & 0.017 & 0.012 & 0.009 & 0.005 \\
\hline $\begin{array}{l}\text { Trichloroethane/ } \\
\text { silica alumina } 35^{\circ} \mathrm{C}\end{array}$ & 0.017 & 0.013 & 0.009 & 0.005 & 0.003 \\
\hline
\end{tabular}




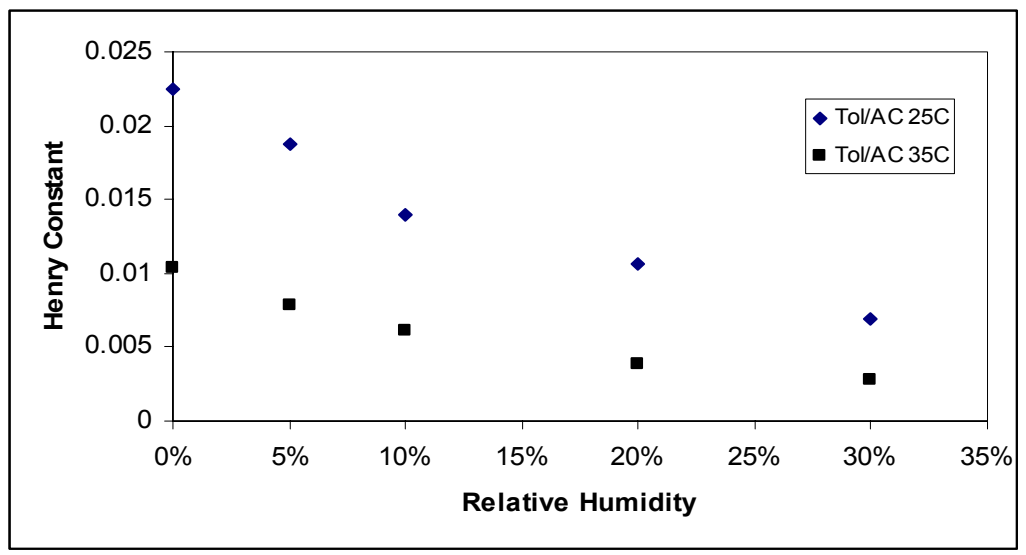

Figure 4: Henry constant as a function of relative humidity.

\section{Conclusion}

The following conclusions can be addressed:

- The Henry constant decreased with increasing temperature since adsorption decreases and desorption increases.

- Toluene had a higher equilibrium Henry constant compared to trichloroethane on silica alumina and activated silica.

- Trichloroethane had a higher equilibrium Henry constant compared to toluene on activated carbon.

- The highest equilibrium Henry constants were observed on activated silica alumina.

- Similar values of Henry constant were observed with activated carbon granules and pellets.

- Henry constant decreases with increasing relative humidity since the moisture occupies some of the sites available for adsorption and hence decreases the VOC adsorption capacity.

\section{Acknowledgement}

The authors gratefully acknowledge the financial support of Kuwait University Research Administration (Grant No. EC02/00), which made this work possible.

\section{References}

[1] Bouhamra W.S., Elkilani A.S. and Raheem M.Y. Analysis of Indoor Concentration of Benzene using an Air Quality Model, Archives of Environmental Health,55,3, 2000. 
[2] Buhamra S., Bouhamra W. and Elkilani A. Assessment of Indoor Air Quality in Ninety-Nine Residences of Kuwait, Environmental Technology, 19,p.357-368, 1998.

[3] Elkilani A., Bouhamra W. and Crittenden B. An Indoor Air Quality Model That Includes The Sorption of VOCs on Fabrics, Trans IchemE, 79(B), pp. 233-243, 2001.

[4] Ruthven M.D. Principles of Adsorption and Desorption Processes, John Wiley \& Sons, New York. 1984. 